\title{
Effects of vaginal administration of conjugated estrogens tablet on sexual function in postmenopausal women with sexual dysfunction: a double-blind, randomized, placebo-controlled trial
}

\author{
Thanapob Bumphenkiatikul ${ }^{1 *}$ (D, Krasean Panyakhamlerd ${ }^{1}$, Thanittha Chatsuwan², Chai Ariyasriwatana ${ }^{3}$,
} Ammarin Suwan ${ }^{1}$, Charoen Taweepolcharoen ${ }^{1}$ and Nimit Taechakraichana ${ }^{4}$

\begin{abstract}
Background: Female sexual dysfunction (FSD) is prevalent in women with genitourinary syndrome of menopause (GSM). Vaginal estrogen is effective GSM treatment. This study was primarily aimed to evaluate the effects of vaginal administration of conjugated estrogens tablet on postmenopausal FSD using the Female Sexual Function Index (FSFI). Secondary aims were to evaluate vaginal pH, Vaginal Maturation Value (VMV), Normal Flora Index (NFI) and Most Bothersome Symptoms (MBS) changes.

Methods: A double-blind trial was conducted in postmenopausal women with FSD (FSFI $\leq 26.55$ ). Sixty-seven participants were randomized into two arms; vaginally administered conjugated estrogens tablet $(0.625 \mathrm{mg}$, daily for 3 weeks then twice weekly for 9 weeks, $n=33)$, or placebo $(n=34)$.
\end{abstract}

Results: There was no significant improvement of FSFI observed in estrogens arm compared to placebo in each domain and overall index $(p=0.182)$. The estrogens significantly improved vaginal $\mathrm{pH}$ and VMV, toward more acidity $(p=<0.001)$, higher VMV $(p=<0.001)$ and more superficial cells $(p=<0.001)$. We observed no significant difference in NFI and MBS between arms ( $p=0.282,0.182$ ).

Conclusion: We found no significant changes in FSFI, NFI, and MBS, but significant improvement in vaginal pH and VMV in postmenopausal women with FSD treated with vaginally administered conjugated estrogens tablet. Few side-effects were reported.

Trial registration: Thai Clinical Trial Registry identification number TCTR20180219001, prospectively registered since 2018-02-19 11:33:21.

Keywords: Sexual dysfunction, Vulvovaginal atrophy, Genitourinary syndrome of menopause, Dyspareunia, Hormonal therapy, Vaginal pH, Vaginal maturation index, The female sexual function index

\footnotetext{
*Correspondence: thanapob@chula.md

'Division of Reproductive Medicine, Department of Obstetrics and

Gynecology, Faculty of Medicine, Chulalongkorn University, 1873 Rama IV Road, Bangkok 10330, Thailand

Full list of author information is available at the end of the article
}

(C) The Author(s). 2020 Open Access This article is licensed under a Creative Commons Attribution 4.0 International License, which permits use, sharing, adaptation, distribution and reproduction in any medium or format, as long as you give appropriate credit to the original author(s) and the source, provide a link to the Creative Commons licence, and indicate if changes were made. The images or other third party material in this article are included in the article's Creative Commons licence, unless indicated otherwise in a credit line to the material. If material is not included in the article's Creative Commons licence and your intended use is not permitted by statutory regulation or exceeds the permitted use, you will need to obtain permission directly from the copyright holder. To view a copy of this licence, visit http://creativecommons.org/licenses/by/4.0/. The Creative Commons Public Domain Dedication waiver (http://creativecommons.org/publicdomain/zero/1.0/) applies to the data made available in this article, unless otherwise stated in a credit line to the data. 


\section{Background}

Female sexual dysfunction (FSD) is an important condition which prevalence is difficult to estimate [1] and thought to be underreported. A 2005-report showed that 38 to $63 \%$ of women all over the world suffered from FSD [2]. The prevalence of FSD increases with age [3]. In a southern province of Thailand, the proportion of postmenopausal women diagnosed with sexual dysfunction based on FSFI overall scores of 26.5 or less was $82.2 \%[4]$.

According to DSM-5 criteria, FSD is classified into three major categories: female sexual interest/arousal disorders (FSIAD), female orgasmic disorder and genitopelvic pain/penetration disorder (GPPPD) [5]. It was postulated that there were links between all three categories in etiology and also treatment, i.e., if the patient is treated for GPPPD, there might be an improvement in FSIAD and vice versa [6].

GPPPD was formerly subdivided into dyspareunia and vaginismus in DSM-IV criteria, but later the two subdivisions were merged together [5]. Dyspareunia in postmenopausal period is generally due to genitourinary syndrome of menopause (GSM), a novel broader term for vulvovaginal atrophy (VVA), encompassing three domains of menopausal change, i.e., sexual, urinary and genital symptoms [7].

GSM is a condition resulting from the hypoestrogenic vaginal epithelium. With less glycogen storage in vaginal epithelium, the vaginal mucosa becomes thinner and vasculature become minimal, causing less transudate in the vagina. Lactobacillus spp., normal flora of vaginal microbiome becomes lack of substrate to produce lactic acid to maintain vaginal acidity; hence, the menopause vagina becomes dry, pale, thin, basic, and colonized with pathologic bacteria instead of Lactobacillus spp. as compared to premenopausal women [8]. This phenomenon is the cause of dyspareunia during postmenopause. The gold standard of GSM treatment is hormonal therapy, preferably with local estrogen application to avoid unwanted systemic effect particularly when there is no FDA approved indication for systemic hormone therapy [9-12].

There are several preparations of vaginal estrogen for treating GSM. Conjugated estrogens tablet $(0.625 \mathrm{mg})$ has been listed in the Thai National List of Essential Medicines 2018 for use as female sex hormone while conjugated estrogens vaginal cream listed for Treatment of vaginal and vulval conditions [13]. However, conjugated estrogens vaginal cream is not available in Thailand, driving patients and physicians to seek alternative treatment for GSM.

In the past decades, there have been questions of whether the official labelled oral estrogens can be used to treat GSM via vaginal administration. Several studies were conducted both in postmenopausal and premenopausal women showing that the benefits from vaginal administration of several oral estrogens were not inferior to standard oral administration [14-16]. To our knowledge, there were no published studies on the use of the country-wide available conjugated estrogens tablet in improving FSD with vaginal administration. Therefore, the primary objective of the present study was to evaluate the effects of vaginal administration of conjugated estrogens tablet on sexual function in postmenopausal women with FSD using the Female Sexual Function Index (FSFI). The secondary objectives were to evaluate changes in vaginal $\mathrm{pH}$, Vaginal Maturation Value (VMV), Normal Flora Index (NFI) and any possible side effects of the treatment. If vaginal administration of conjugated estrogens tablet could improve sexual function in postmenopausal women with FSD, this low-cost, easy-to-use and widely available estrogens would be an interesting treatment option to improve this prevalent condition.

\section{Methods \\ Design}

The study was designed as a single-center, prospective, double-blind, randomized, placebo-controlled trial, which randomized participants into two groups in a 1:1 ratio. The study adhered to CONSORT guidelines and was approved by the Institutional Review Board of the Faculty of Medicine, Chulalongkorn University (IRB No. 039/2561). The study was also reviewed by the Thai Clinical Trial Registry Committee and prospectively approved for registration since 2018-02-19 11:33:21 and Thai Clinical Trial Registry identification number TCTR20180219001. After approval, participants were included from August 2018 to March 2019. A thorough explanation of the study details was given to all enrolled women. Informed written consent was obtained prior to the start of the study.

\section{Patient recruitment}

Literate Thai women aged 45-70 years who experienced spontaneous menopause attending the General Gynecologic Clinic, Climacteric and Gender Health Clinic at King Chulalongkorn Memorial Hospital were recruited. Menopause was defined according to WHO criteria as the cessation of the period for at least 12 consecutive months [17].

\section{Inclusion and exclusion criteria}

These women were asked for their vaginal atrophy symptoms and other detailed histories. Participants were included if they reported at least one self-assessed vaginal atrophy symptom in moderate or severe intensity and reported engaging in penile-vaginal penetrative sexual intercourse at least once a month. Those with pathological or surgical causes of menopause, using menopausal hormone 
therapy (MHT) or non-hormonal treatment that might affect the vaginal epithelium, having abnormal vaginal bleeding/discharge without prior appropriate investigation and treatment, cervical or vaginal surgical history within the previous 3 months, history of sex steroid hormone use 2 months prior to study, history of psychiatric disorders or having partner with sexual dysfunction, contraindications for MHT including personal or family history of estrogenrelated cancer, severe liver or kidney diseases and any suspected allergy to MHT, were excluded from the study. The recruited subjects were then asked to complete a 19item Thai version of the Female Sexual Function Index questionnaire, and those that scored $>26.55$ points were then excluded as having no FSD. The Thai version of the Female Sexual Function Index questionnaire was validated in previous study among Thai postmenopausal women, aged 40-60 years, with high reliability coefficients and internal consistency $(r=0.79-0.86$, Cronbach's alpha value $=$ 0.82) [18]. After pelvic examination and test for vaginal $\mathrm{pH}$, those with $\mathrm{pH}$ more than 5 were qualified for the study as they were likely to have poor estrogenic vaginal mucosa and might benefit from the treatment.

\section{Randomization and blinding}

A computer generated block of four randomizations was used to randomize participants into two groups in a 1:1 ratio. The allocation and concealment of placebo and the drugs into identical opaque envelopes were done by a nurse who was not involved in contacting with patients or analyzing any data, thus blinding investigators, assessors, cytologist, microbiologist and all participants.

\section{Sample size justification}

The sample size of this study was estimated based on our pilot study, conducted with 10 participants enrolled in both arms. The following formula was used for comparing continuous data in a randomized controlled trial [19].

$$
n_{t r t}=\frac{\left(z_{1-\frac{\alpha}{2}}+z_{1-\beta}\right)^{2}\left[\sigma_{t r t}^{2}+\frac{\sigma_{c o n}^{2}}{r}\right]}{\Delta^{2}}
$$

According to our pilot study, $\mu$ trt (mean value) and otrt (standard deviation) of total FSFI at 12 week follow up in treatment group were 26.8 and 5.7, respectively; $\mu$ con and $\sigma$ con of total FSFI at 12 week follow up in control group were 23.0 and 4.7, respectively. The ratio between groups $(\mathrm{r})$ was set as 1 for 1:1. With using $\alpha=$ 0.05 and $\beta=0.2$, the sample size needed for this study was 30 participants per group. Predicting a 10\% drop out rate, the sample size was increased to 33 participants per group.

\section{Intervention}

After completion of history taking and filling all the questionnaires, participants who met the inclusion criteria mentioned above were asked to undergo a pelvic examination, all conducted by single investigator (T.B.). A dry speculum was inserted without lubrication. A pHindicator strip ( $\mathrm{pH}$ range 0-14, Merck, Germany) was placed over the upper to the middle third of the lateral vaginal wall with contact time between the $\mathrm{pH}$-indicator strip and the examined vaginal wall for $3 \mathrm{~s}$.

Two dry cotton buds were used to scrape contralateral vaginal wall. Each cotton bud was smeared onto each different glass slide. One slide was left to air dry and sent for evaluation of Normal Flora Index (NFI) with Gram staining by single microbiologist (T.C.), unaware of treatment allocation, participant symptoms and characteristics. NFI, representing vaginal microenvironment, consisted of 4 parameters, i.e., the number of lactobacilli, pathogenic microorganisms, leukocytes, and vaginal $\mathrm{pH}$. Each parameter was graded on a 4-point scale (Table 1). Pathogenic microorganisms included Gardnerella, Bacteroides, Mobiluncus and gram-variable bacilli [21, 22].

The other slide was fixed with $95 \%$ ethanol solution for $30 \mathrm{~min}$ and sent for staining in accordance with Papanicolaou test. The slide was evaluated for Vaginal Maturation Value (VMV) by single cytologist (C.A.), unaware of treatment allocation, participant symptoms/ characteristics. VMV, calculated from the formula: (\% of intermediate cells $\times 0.5)+(\%$ of superficial cells $\times 1)$, is considered as a surrogate of vaginal epithelium estrogen status [23, 24-26].

The number of lactobacilli, pathogenic microorganisms and VMV was evaluated under the microscope with 1000x magnification (HPF). The number of leukocytes was evaluated under the microscope with $400 x$ magnification.

Participants were then examined with transvaginal ultrasonography for baseline endometrial thickness [Samsung SONOACE R7, 2D imaging mode, grayscale 256 (8 bits), EVN4-9 probe $3.5 \mathrm{MHz}$, single operator (T.B.)]. Blood samples were taken for baseline hematocrit, SGOT, SGPT, alkaline phosphatase, total cholesterol, LDL, HDL, triglycerides and estradiol level. The samples were analyzed immediately, or stored at 4 degrees Celsius until analysis no more than $24 \mathrm{~h}$ later. All blood sample analyses were done with routine laboratory testing platform for research projects at the King Chulalongkorn Memorial Hospital, strictly adhering to the manufacturers' protocol and in accordance with the laboratory's standard operating procedures for good laboratory practice.

After the recruitment process, participants were randomized into the conjugated estrogens or the placebo groups. The estrogens or placebo was given in numbered 
Table 1 The Female Sexual Function Index scoring system [20]

\begin{tabular}{|c|c|c|c|c|c|}
\hline Domain & Questions & Score range & Factor & Minimum score & Maximum score \\
\hline desire & 1,2 & $1-5$ & 0.6 & 1.2 & 6 \\
\hline arousal & $3,4,5,6$ & $0-5$ & 0.3 & 0 & 6 \\
\hline lubrication & $7,8,9,10$ & $0-5$ & 0.3 & 0 & 6 \\
\hline orgasm & $11,12,13$ & $0-5$ & 0.4 & 0 & 6 \\
\hline satisfaction & $14,15,16$ & 0 (or 1) -5 & 0.4 & 0.8 & 6 \\
\hline pain & $17,18,19$ & $0-5$ & 0.4 & 0 & 6 \\
\hline \multicolumn{4}{|c|}{ Full-scale score range } & 2 & 36 \\
\hline
\end{tabular}

as identical opaque envelopes with instruction leaflet. The treatment arm was conjugated estrogens tablet (EstromonTM, $0.625 \mathrm{mg}$ ). The placebo arm was lactose $90 \%$, polyvinyl pyrrolidone K30 5\%, magnesium stearate $3 \%$, talcum $1 \%$ erythrosinelahe dye $1 \%$ and water which was evaporated completely during manufacturing. The placebo was made by the Faculty of Pharmaceutical Science, Chulalongkorn University and was visually identical to the conjugated estrogens tablet. No participants reported allergic reactions to lactose, talcum or any substances used in the study. Participants were required to insert each pill vaginally as deeply as possible every day for 3 weeks. After 3 weeks of participation, the investigator called to each participant to check on adherence, problems of drug administration or adverse reactions and willingness to continue the study, after which participants were advised to continue the study by inserting a pill vaginally twice weekly on every Monday and Friday night for the next 9 weeks. The regimen was extrapolated from recommendation for treating dyspareunia with conjugated estrogen vaginal cream [11].

After the 12th week of study, each participant came back for reevaluation of symptoms, filling out questionnaires, undergoing pelvic examination for vaginal $\mathrm{pH}$, smear for NFI and VMV, transvaginal ultrasonography and blood samples.

\section{Outcome measures}

The primary outcome of this study was the changes of FSFI of the two treatment arms. FSFI was one of the validated standard questionnaires frequently used for assessing female sexual function and quality of life in clinical trials or epidemiological studies concerning sexual study $[20,27]$. Since there were no validated measurement tools specifically designed for female sexual function and dysfunction in menopausal population, and FSFI was frequently used in researches concerning female sexual function and quality of life in menopausal population, the index was selected for this study. The questionnaires consisted of 19 self-reporting rating-scale items, assessing 6 domains of sexual function; desire, arousal, lubrication, orgasm, satisfaction and pain. Each item has a scaled response ranging from 0 to 5 or 1 to 5 ; with higher scores representing better sexual function (Table 1). Each domain score is calculated by summation of scores from every item in the domain multiplied by the domain factor (i.e., 0.6 for desire, 0.3 for arousal and lubrication, 0.4 for orgasm, satisfaction and pain), thus the full score of each domain is 6. The possible full scores of total FSFI ranges from 2.0 to 36.0, with cut-off point of 26.55 or less considered FSD in premenopausal and postmenopausal women population [28]. However, there is no specific cut-off score for FSD in a population with GSM [29].

Secondary outcomes were changes in vaginal $\mathrm{pH}$, VMV, NFI, and the Most Bothersome Symptoms (MBS). The MBS, also known as the vaginal atrophy symptoms consists of 4 symptoms; vaginal dryness, vaginal/vulvar irritation/itching, vaginal/vulvar soreness, and dyspareunia. Each symptom is self-graded by participants on a 4 -point scale $(0=$ no symptom, $1=$ mild, $2=$ moderate, 3 = severe) [30]. Only those reported at least one selfassessed vaginal atrophy symptom in moderate or severe intensity were included. The safety parameters assessed were changes in hematocrit, SGOT, SGPT, alkaline phosphatase, total cholesterol, LDL, HDL, triglycerides, estradiol level and endometrial thickness.

\section{Statistical analysis}

IBM SPSS $^{\text {TM }}$ statistics version 18.0 for Windows was used for statistical analysis. The treatment effect was evaluated with intention-to-treat analysis, with missing data assumed by multiple imputation method. Baseline demographic characteristics were presented using descriptive statistics; mean and standard deviation (SD), median and interquartile range (IQR), or number and percentage as appropriate. Primary and secondary outcome comparisons between groups were evaluated with Mann-Whitney $U$ test or analysis of covariance (ANCOVA), with treatment arm as a fixed effect in the model and the baseline value used as a covariate, according to data distribution characteristics. P-value of less than 0.05 is determined statistically significant. 


\section{Results}

From August,10th 2018 to March, 18th 2019, a total of 67 participants were enrolled in the study. The enrollment was stopped when the number of participants meet the calculated sample size. Thirty-four participants were randomized into the estrogens arm while another 33 were randomized into the placebo arm (Fig. 1). Fiftyeight participants completed the study, all with compliance of $>90 \%$ based on pills count on follow up visit. Frequency of sexual intercourses during 12 weeks was reported to be more than once monthly in both groups. Nine participants, 5 in the estrogens arm and 4 in the placebo arm, discontinued from the study during the 12week protocol. In those who discontinued participating in the treatment arm, two participants change their mind due to concern about the effect of the treatment, one participant reported breast tenderness and withdrawn consent, one participant reported lack of sexual intercourse which met the exclusion criteria, and one participant lost the follow up visit with no response from available contacts. In those who discontinued participating in the placebo arm, three participants change their mind due to concern about the effect of the treatment and withdrawn consent, and one participant move out of the country and cannot return for the second visit. Demographic data and baseline characteristics were comparable with no statistically differences between the two arms of the study (Table 2); with the mean age of participants at $57.41 \pm 4.85$ and $57.03 \pm 4.65$ years; and mean body mass index of $24.62 \pm 3.48$ and $25.09 \pm 3.97 \mathrm{~kg} / \mathrm{m}^{2}$ in the estrogens and placebo arms, respectively.

\section{Primary outcome: sexual function}

No significant improvement of the Female Sexual Function Index was observed after using conjugated estrogens for 12 weeks compared to placebo in all six domains and overall index $(p=0.182)$. (Table 3$)$.

\section{Secondary outcome: vaginal $\mathrm{pH}, \mathrm{VMV}, \mathrm{NFI}$ and MBS}

Vaginal administration of oral conjugated estrogens tablets could statistically significant improve vaginal $\mathrm{pH}$ toward more acidity $(p=<0.001)$ with higher Vaginal Maturation Value $(p=<0.001)$ and superficial cells $(p=$ $<0.001$ ). (Table 3) There was no significant difference in NFI between both arms $(p=0.282)$. No significant improvement of MBS, both in total scores $(p=0.182)$ and each symptom, was observed. (Table 3 ).

\section{Safety parameters}

At the end of the study, there were no significant differences in hematocrit, SGOT, SGPT, alkaline phosphatase, total cholesterol, triglycerides, LDL, HDL, estradiol level and endometrial thickness between the two groups after adjusted for baseline parameter. Only triglycerides were found to be higher in the placebo group after the 12week treatment $(p=0.045)$ (Table 4$)$.

The number of participants reporting adverse events was comparable between the estrogens (51.72\%) and placebo arms (41.38\%) (Table 5). The most common adverse event in the estrogens arm was breast tenderness (31.03\%) of which prompted two participants to withdraw from the study. Surprisingly, the most common adverse event in the placebo arm was also breast tenderness $(28.00 \%)$. One participant who reported no adverse event on the third week of follow-up phone call could not be contacted at the end of the study.

\section{Discussion}

This was a 12-week double-blind, randomized, placebocontrolled trial designed to evaluate the effects of vaginal administration of conjugated estrogens tablet on sexual

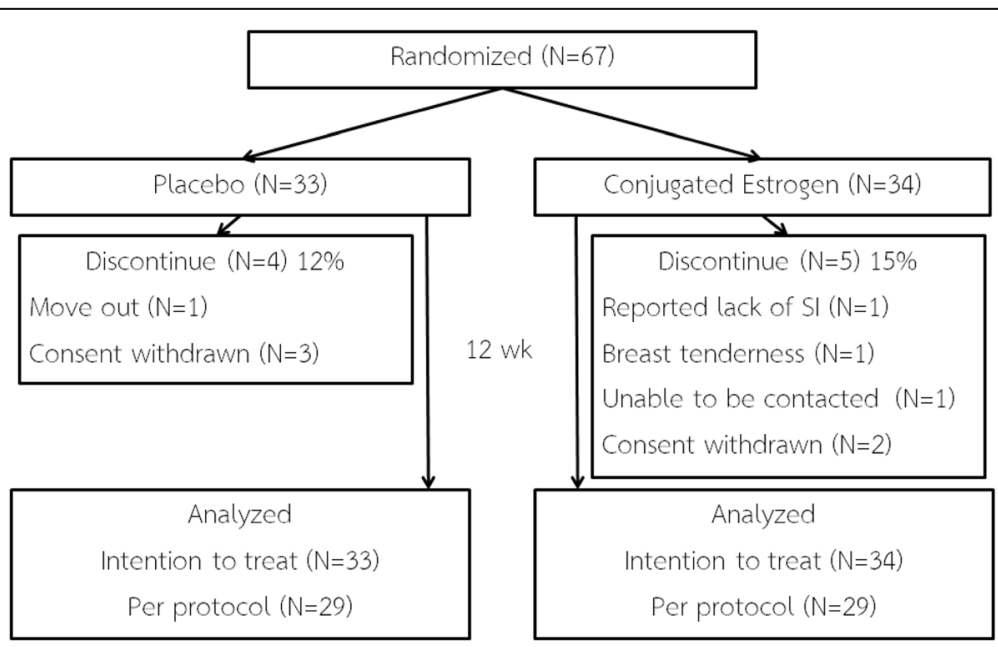

Fig. 1 Protocol flow diagram 
Table 2 Demographic data and baseline characteristics of all participants ( $N=67)$

\begin{tabular}{|c|c|c|}
\hline Parameter & $\begin{array}{l}\text { Estrogens group* } \\
(n=34)\end{array}$ & $\begin{array}{l}\text { Placebo group } \\
(n=33)\end{array}$ \\
\hline Age (years) ${ }^{a}$ & $57.41 \pm 4.85$ & $57.03 \pm 4.65$ \\
\hline Menopausal age (years) ${ }^{a}$ & $50.74 \pm 3.46$ & $50.30 \pm 3.04$ \\
\hline Year since menopause (years) ${ }^{a}$ & $6.68 \pm 4.52$ & $6.73 \pm 4.03$ \\
\hline BMI $\left(\mathrm{kg} / \mathrm{m}^{2}\right)^{\mathrm{a}}$ & $24.62 \pm 3.48$ & $25.09 \pm 3.97$ \\
\hline Pregnancies (times) ${ }^{a}$ & $2.32 \pm 1.34$ & $2.30 \pm 1.31$ \\
\hline Deliveries (times) $)^{a}$ & $1.91 \pm 1.16$ & $1.88 \pm 0.93$ \\
\hline Reported sexual intercourse (times/month) ${ }^{c}$ & $2(1-3)$ & $3(1-8)$ \\
\hline \multicolumn{3}{|l|}{ Education $^{\mathrm{b}}$} \\
\hline Elementary school or less & $11(33.3 \%)$ & $11(32.4 \%)$ \\
\hline Secondary school or diploma & $14(41.18 \%)$ & $13(39.39 \%)$ \\
\hline Higher education & $9(26.47 \%)$ & $9(27.27 \%)$ \\
\hline \multicolumn{3}{|l|}{ Times of marriage ${ }^{b}$} \\
\hline Once & $30(88.24 \%)$ & $24(72.74 \%)$ \\
\hline Twice & $4(11.76 \%)$ & $9(27.27 \%)$ \\
\hline Duration of marriage (years) ${ }^{c}$ & $30(25.5-33)$ & $30(22.5-37.5)$ \\
\hline Vaginal $\mathrm{pH}^{c}$ & $6(5.5-8.0)$ & $6(5.5-6.0)$ \\
\hline Vaginal Maturation Value ${ }^{c}$ & $150-50)$ & $15(1.25-47.5)$ \\
\hline
\end{tabular}

${ }^{*}$ conjugated estrogens

${ }^{\mathrm{a}}$ mean $\pm \mathrm{SD},{ }^{\mathrm{b}}$ number (\%), ${ }^{\mathrm{C}}$ median (interquartile range, $\mathrm{QQR}$ )

Table 3 Primary and secondary outcomes (Intention-to-treat analysis, $n=67$ )

\begin{tabular}{|c|c|c|c|c|c|}
\hline \multirow[t]{2}{*}{ Parameter } & \multicolumn{2}{|c|}{ Estrogens group* $(n=34)$} & \multicolumn{2}{|c|}{ Placebo group $(n=33)$} & \multirow[t]{2}{*}{$P$-value } \\
\hline & Week 0 & Week 12 & Week 0 & Week 12 & \\
\hline FSFI: Total ${ }^{a}$ & $20.31 \pm 4.93$ & $25.14 \pm 4.74$ & $22.27 \pm 5.03$ & $24.32 \pm 4.83$ & 0.182 \\
\hline FSFI: Desire ${ }^{a}$ & $2.44 \pm 0.82$ & $3.12 \pm 0.76$ & $2.73 \pm 0.65$ & $2.90 \pm 0.64$ & 0.218 \\
\hline FSFI: Arousal ${ }^{a}$ & $2.72 \pm 1.06$ & $3.46 \pm 0.97$ & $3.03 \pm 1.28$ & $3.25 \pm 0.91$ & 0.133 \\
\hline FSFI: Lubrication ${ }^{a}$ & $3.46 \pm 1.27$ & $4.54 \pm 1.16$ & $3.98 \pm 1.04$ & $4.20 \pm 1.03$ & 0.057 \\
\hline FSFI: Orgasm ${ }^{a}$ & $3.93 \pm 1.14$ & $4.26 \pm 1.24$ & $4.10 \pm 1.12$ & $4.62 \pm 1.16$ & 0.365 \\
\hline FSFI: Satisfaction ${ }^{a}$ & $4.06 \pm 1.02$ & $4.63 \pm 0.88$ & $4.52 \pm 0.85$ & $4.69 \pm 0.99$ & 0.219 \\
\hline FSFI: Pain ${ }^{a}$ & $3.71 \pm 1.87$ & $5.13 \pm 0.95$ & $3.90 \pm 1.51$ & $4.66 \pm 1.05$ & 0.067 \\
\hline Vaginal $\mathrm{pH}^{\mathrm{c}}$ & $6.0(5.5-8.0)$ & $5.0(4.0-6.0)$ & $6.0(5.5-6.0)$ & $7.0(6.0-8.0)$ & $<0.001$ \\
\hline Normal Flora Index ${ }^{c}$ & $5(3-6)$ & $6(4-10)$ & $4(3-6)$ & $6(4-6)$ & 0.282 \\
\hline Vaginal Maturation Value ${ }^{c}$ & $15(0-53.75)$ & $57.5(38.75-65)$ & $20(1.25-51.25)$ & $20(0.63-46.88)$ & $<0.001$ \\
\hline Superficial cell ${ }^{\mathrm{C}}$ & $0(0-1)$ & $0.5(1.5-3)$ & $0(0-2.5)$ & $0(0-0.88)$ & $<0.001$ \\
\hline MBS, total ${ }^{c}$ & $4(3-6)$ & $2(0-3)$ & $5(3-7)$ & $3(1-4)$ & 0.182 \\
\hline Vaginal dryness ${ }^{c}$ & $2(2-3)$ & $1(0-2)$ & $2(2-3)$ & $1(0-2)$ & 0.858 \\
\hline Vaginal/vulvar irritation/itching ${ }^{c}$ & $0(0-2)$ & $0(0-0)$ & $1(0-2)$ & $0(0-1)$ & 0.190 \\
\hline vaginal/vulvar soreness ${ }^{c}$ & $0(0-1)$ & $0(0-0)$ & $0(0-2)$ & $0(0-1)$ & 0.204 \\
\hline Dyspareunia $^{c}$ & $2(1-3)$ & $0(0-1)$ & $2(1-2)$ & $1(0-1)$ & 0.152 \\
\hline
\end{tabular}

*conjugated estrogens

${ }^{a}$ mean \pm SD Data was analyzed by ANCOVA, ${ }^{b}$ number (\%), ${ }^{c}$ median (interquartile range, IQR) Data was analyzed by Mann-Whitney $U$ test

Data shown in bold indicates statistical significance $(p<0.05)$

FSFI the Female Sexual Function Index, MBS Most Bothersome Symptoms 
Table 4 Safety outcomes (Intention-to-treat analysis, $n=67)^{\text {a }}$

\begin{tabular}{|c|c|c|c|c|c|}
\hline \multirow[t]{2}{*}{ Parameter } & \multicolumn{2}{|c|}{$\begin{array}{l}\text { Estrogens group* } \\
(n=34)\end{array}$} & \multicolumn{2}{|l|}{$\begin{array}{l}\text { Placebo group } \\
(n=33)\end{array}$} & \multirow[t]{2}{*}{$\begin{array}{l}P \text { - } \\
\text { value }\end{array}$} \\
\hline & Week 0 & Week 12 & Week 0 & Week 12 & \\
\hline Hematocrit (\%) $)^{\mathbf{a}}$ & $39.42 \pm 3.30$ & $38.68 \pm 2.51$ & $39.36 \pm 3.23$ & $38.63 \pm 3.06$ & 0.655 \\
\hline SGOT (unit/L) ${ }^{a}$ & $28.72 \pm 12.05$ & $27.10 \pm 15.48$ & $23.79 \pm 9.72$ & $24.96 \pm 9.62$ & 0.390 \\
\hline SGPT (unit/L) $)^{\mathbf{a}}$ & $29.86 \pm 16.90$ & $30.31 \pm 20.95$ & $24.33 \pm 14.03$ & $29.33 \pm 15.74$ & 0.279 \\
\hline ALP (unit/L) $)^{\mathbf{a}}$ & $77.07 \pm 29.42$ & $76.69 \pm 22.15$ & $77.75 \pm 20.91$ & $79.38 \pm 18.25$ & 0.809 \\
\hline Total cholesterol $(\mathrm{mg} / \mathrm{dL})^{\mathbf{a}}$ & $215.72 \pm 37.62$ & $212.93 \pm 38.03$ & $215.04 \pm 39.35$ & $218.00 \pm 38.20$ & 0.733 \\
\hline Triglycerides (mg/dL) ${ }^{\mathbf{a}}$ & $123.69 \pm 45.37$ & $114.93 \pm 52.79$ & $126.71 \pm 64.49$ & $162.33 \pm 97.69$ & 0.045 \\
\hline $\mathrm{HDL}(\mathrm{mg} / \mathrm{dL})^{\mathbf{a}}$ & $57.21 \pm 10.52$ & $58.72 \pm 12.75$ & $56.63 \pm 11.91$ & $54.29 \pm 11.41$ & 0.142 \\
\hline $\mathrm{LDL}(\mathrm{mg} / \mathrm{dL})^{\mathbf{a}}$ & $134.00 \pm 34.56$ & $131.17 \pm 33.37$ & $133.13 \pm 36.19$ & $131.21 \pm 39.52$ & 0.825 \\
\hline Endometrial thickness $(\mathrm{mm})^{\mathbf{a}}$ & $3.28 \pm 2.03$ & $3.38 \pm 1.97$ & $3.44 \pm 2.30$ & $3.15 \pm 1.72$ & 0.677 \\
\hline Estradiol $(\mathrm{pg} / \mathrm{mL})^{\mathbf{b}}$ & $5.00(5.00,11.94)$ & $5.00(5.00,9.61)$ & $5.00(5.00,12.96)$ & $5.00(5.00,9.89)$ & 0.218 \\
\hline
\end{tabular}

${ }^{*}$ conjugated estrogens

amean \pm SD Data was analyzed by ANCOVA,

${ }^{b}$ median (interquartile range, IQR) Data was analyzed by Mann-Whitney U test

Data shown in bold indicates statistical significance $(p<0.05)$

function in postmenopausal women with female sexual disorders (FSD). The results showed that vaginal administration of conjugated estrogens tablet significantly improved vaginal $\mathrm{pH}$ and Vaginal Maturation Value, toward more superficial cells. However, there was no significant difference in the Female Sexual Function Index (FSFI) after 12 weeks between the two groups in each domain and overall index. Also there was no significant difference in Normal Flora Index (NFI), and the Most Bothersome Symptoms (MBS) between the two groups.

The treatment drugs, conjugated estrogens tablet (EstromonTM, $0.625 \mathrm{mg}$ ), is a combination of Cynanchum wilfordii Hemsley, Phlomis umbrosa Turczaninow, and Angelica gigas Nakai extracts (CPAE). A one-year clinical study in South Korea [31] and another randomized, double-blinded, placebo-controlled clinical study in non-Asian American women [32] confirmed that the formula, administered orally, significantly ameliorated various menopausal symptoms without any serious side effects, increase in body weight, body mass index (BMI) or changes of serum levels of estradiol (E2), follicle stimulating hormone $(\mathrm{FSH})$ and liver enzymes.

Table 5 Adverse event [number (\%)]

\begin{tabular}{lll}
\hline Parameter & $\begin{array}{l}\text { Estrogens group* } \\
(\boldsymbol{n}=\mathbf{2 9 )}\end{array}$ & $\begin{array}{l}\text { Placebo group } \\
(\boldsymbol{n}=\mathbf{2 9})\end{array}$ \\
\hline Any adverse events & $15(51.72 \%)$ & $12(41.38 \%)$ \\
Breast tenderness & $9(31.03 \%)$ & $7(28.00 \%)$ \\
Vaginal discharge & $4(13.79 \%)$ & $4(13.79 \%)$ \\
Insoluble pill & $7(24.14 \%)$ & $4(13.79 \%)$ \\
New onset of vaginal itching & $4(13.79 \%)$ & $0(0 \%)$ \\
\hline
\end{tabular}

*conjugated estrogens
Several oral medications have been off-label administered vaginally to treat conditions when the oral route was intolerable. These include misoprostol for induction of labor, cervical ripening, and pregnancy termination; sildenafil to increase blood flow to the uterus in preparation for embryo implantation; bromocriptine for treatment of prolactinoma in those intolerant of nausea/vomiting side effects; oral contraceptives [33-35] and oral hormone therapy preparations for those with intolerable side effects from oral administration [36]. Advantages of the vaginal route include avoidance of the hepatic first-pass effect, thus enabling lower dose administration. The vaginal absorption is unaffected by and can also avoid gastrointestinal disturbances. Less frequent administrations are required than the oral route [37].

Two factors which determine drug absorption from vagina include drug dissolvability and vaginal membrane penetration. These steps are influenced by vaginal physiological factors and physicochemical properties of drugs [38]. Vaginal estrogen was found to be better absorbed by thinner mucosa in postmenopausal women [39]. In addition, the estrogenization of the vaginal mucosa, evidenced from the increase of VMV toward more presence of superficial cells in this study, could also improve absorption of hormones through the vaginal wall $[40,41]$. Nevertheless, data was very limited for the relationship between drug physicochemical properties and the human vaginal permeability. As a matter of fact, CPAE with its lipophilic property may have better affinity for vaginal absorption.

There were several studies demonstrated beneficial effects of estrogens, specifically designed to be administered vaginally, on female sexual function and quality of life $[42,43]$. This study was designed to be a pioneer of 
using oral medication, off-labelly administered vaginally to treat FSD. Though the vaginal conjugated estrogens in this study could significantly decrease vaginal $\mathrm{pH}$ and improved VMV toward superficial cell domination, there was no statistically significant difference between the two groups in FSFI, NFI and MBS. This is probably due to the fact that sexual function, particularly during postmenopause, is multifactorial. Biological, psychological factors and relationship with partner may have complex interplay on sexual outcome. The use of vaginal estrogens to improve biological conditions of the vagina might not be able to reveal overall effects on clinical indicators such as FSFI and MBS. On the other hand, our pilot study for sample size calculation may not be homogenous with the studied population to render a meaningful result in this study. Moreover, the insignificant improvement of our primary outcome might be due to less-than-expected absorption of the oral estrogen tablet in vagina. Lastly, the switching to longer interval of vaginal estrogens administration after 3 weeks may compromise any discernible clinical outcome which may result from the treatment effect if it does exist. Thus, more often administration of vaginal estrogens or longer duration of the treatment might result in balanced vaginal microbiome, decreased likelihood of GSM, improvement of sexual function and better quality of life in postmenopausal women with female sexual dysfunction (FSD).

For safety concerning potential adverse estrogenic activity of the CPAE, a study [44] in a stably transfected transcriptionally activated human estrogen receptor (hER)-HeLa9903 cell model showed no significant selective activity against $h E R \alpha$ and $h E R \beta$. The study also showed that CPAE did not increase uterine wet weight in ovariectomized rats, and did not significantly induce MCF-7 cell proliferation, compared with the effects of the positive control E2. The MCF-7 cell line was known to be a hormone-dependent breast cancer cell line that expresses both ER $\alpha$ and ERß. This implied that CPAE was less likely to affect the development of E2-mediated breast cancer cell line.

At the end of the study, there were no statistically significant differences in hematocrit, SGOT, SGPT, alkaline phosphatase, total cholesterol, LDL, HDL, estradiol level and endometrial thickness between the two groups. Only triglycerides were observed to be statistically gained in the placebo group after 12-week treatment. This is not well understood but it might be a coincidence because this is unlikely to be caused by placebo effect.

The reported adverse events were comparable between the two groups. The most common adverse event in the estrogens arm was breast tenderness (33\%) which prompted two participants to discontinue the study. This was probably due to the rising of circulating estrogen levels from significant vaginal absorption in some particular individual. Likewise, this may be placebo effect which was also shown in the participants of the placebo arm who also experienced breast tenderness in $25 \%$. Nonetheless, breast tenderness was reported only at the beginning of the study and subsided after 3 weeks when the vaginal administration frequency decreased. Overall, there were no statistically significant changes in systemic estradiol level and endometrial thickness.

The strengths of this study include 1) the nature of the double-blind, randomized, placebo-controlled trial which has advantages in minimizing placebo effect 2) the standardized FSFI questionnaire which is widely used for sexual function studies of which the results could be compared 3) this study recruited participants having both objective (baseline $\mathrm{pH}>5$ ) and subjective criteria (symptomatic vaginal atrophy) which were indicated for treatment. 4) Though there were no significant differences in overall clinical indicators such as FSFI and MBS, the differences in certain objective indicators such as VMV and vaginal $\mathrm{pH}$ are encouraging evidence that these low-cost and widely available estrogens may be another treatment option for the GSM if there are more confirmative future studies.

However, there are also some limitations in this study which need to be considered 1) since the study period was limited, the safety and efficacy beyond 12 weeks could not be evaluated 2) since the frequency of vaginal administration was switched from daily to twice weekly after 3 weeks, this might obscure the effects of estrogens when compared to placebo at the end of the 12-week study.

Future double-blind, randomized, placebo-controlled trials with sizable sample of postmenopausal women with GSM are needed. This is to minimize the confounding effects of psychological and partnership factors over the effects of GSM on sexual function indicators.

\section{Conclusion}

The 12-week study with vaginal administration of conjugated estrogens tablet had no demonstrable effects on the changes in the Female Sexual Function Index (FSFI), Normal Flora Index (NFI), and Most Bothersome Symptoms (MBS) in postmenopausal women with female sexual dysfunction (FSD). However, the conjugated estrogens usage in aforementioned protocol were found to improve vaginal $\mathrm{pH}$ and Vaginal Maturation Value toward superficial cells domination. This 12-week use of conjugated estrogens appeared to have few side-effects. More frequent administration or longer duration of the treatment might be required to improve FSFI and MBS in postmenopausal women with female sexual dysfunction (FSD). 


\section{Abbreviations}

BMl: Body Mass Index; E2: Estradiol; FSD: Female Sexual Dysfunction; FSFI: Female Sexual Function Index; FSH: Follicle Stimulating Hormone; FSIA D: Female Sexual Interest/Arousal Disorders; GPPPD: Genitopelvic Pain/ Penetration Disorder; GSM: Genitourinary Syndrome of Menopause; HDL: High-density Lipoprotein; hER: Human Estrogen Receptor; IQR : Interquartile Range; LDL: Low-density Lipoprotein; MBS: Most Bothersome Symptoms; MHT: Menopausal Hormone Therapy; NFI: Normal Flora Index; SD : Standard Deviation; SGOT: Serum Glutamic Oxaloacetic Transaminase; SGPT: Serum Glutamic Pyruvic Transaminase; VMV: Vaginal Maturation Value; WA: Vulvovaginal Atrophy

\section{Acknowledgements}

This study could not be completed without contribution from several parties including medical staffs, nurses and supporting staffs from the Gynecologic Clinic, Division of Climacteric Medicine and Gender Health, Department of Microbiology, Division of Gynecologic Cyto-Pathology at King Chulalongkorn Memorial Hospital. We would like to thank Mrs. Sumanee Nilgate, staff of the microbiology laboratory at King Chulalongkorn Memorial Hospital for her technical expertise. We are indebted to Ajarn Piyalamporn Havanont for her elaborate biostatistics advice.

\section{Authors' contributions}

TB collected the data and samples, performed the ultrasonography, analyzed and interpreted the patient data and was a major contributor in writing and revising the manuscript. KP, AS, CT and NT contributed to the rationale and details of the design of this study. KP and NT also had major role in the final manuscript reviews and feedbacks for several occasions before submission. TC evaluated the glass slides samples for Normal Flora Index (NFI). CA performed the histological examination for Vaginal Maturation Value (VMV). All authors read and approved the final manuscript.

\section{Funding}

The study was supported by THE 90TH ANNIVERSARY OF CHULALONGKORN UNIVERSITY FUND (Ratchadaphiseksomphot Endowment Fund). Scholarship number RA61/062. The funding body had no role in the design of the study and collection, analysis, and interpretation of data and in writing the manuscript.

\section{Availability of data and materials}

The datasets used and/or analyzed during the current study are available from the corresponding author on reasonable request.

\section{Ethics approval and consent to participate}

The study was approved by the Institutional Review Board of the Faculty of Medicine, Chulalongkorn University (IRB No. 039/2561). All data was collected after the participants gave written consent. Enrollment was on voluntary basis and all participants could withdraw themselves from the protocol at any time.

\section{Consent for publication}

Not applicable.

\section{Competing interests}

The authors declare that they have no competing interests.

\section{Author details}

'Division of Reproductive Medicine, Department of Obstetrics and Gynecology, Faculty of Medicine, Chulalongkorn University, 1873 Rama IV Road, Bangkok 10330, Thailand. '2Department of Microbiology, Faculty of Medicine, Chulalongkorn University, Bangkok 10330, Thailand. ${ }^{3}$ Division of Gynecologic Cyto-Pathology, Department of Obstetrics and Gynecology, Faculty of Medicine, Chulalongkorn University, Bangkok 10330, Thailand. ${ }^{4}$ Department of Medical Education and Clinical Research Center, Bumrungrad International Hospital, Bangkok 10110, Thailand.
Received: 19 March 2020 Accepted: 23 July 2020

Published online: 12 August 2020

\section{References}

1. Laumann EO, Paik A, Rosen RC. Sexual dysfunction in the United States: prevalence and predictors. JAMA. 1999;281:537-44.

2. Hisasue $S$, Kumamoto $Y$, Sato $Y$, Masumori $N$, Horita $H$, Kato $R$, et al. Prevalence of female sexual dysfunction symptoms and its relationship to quality of life: a Japanese female cohort study. Urology. 2005;65:143-8.

3. Jaafarpour M, Khani A, Khajavikhan J, Suhrabi Z. Female sexual dysfunction: prevalence and risk factors. J Clin Diagn Res. 2013;7:2877-80.

4. Peeyananjarassri K, Liabsuetrakul T, Soonthornpun K, Choobun T, Manopsilp $P$. Sexual functioning in postmenopausal women not taking hormone therapy in the gynecological and menopause clinic Songklanagarind hospital measured by female sexual function index questionnaire. J Med Assoc Thail. 2008;91:625-32.

5. Sungur MZ, Gunduz A. A comparison of DSM-IV-TR and DSM-5 definitions for sexual dysfunctions: critiques and challenges. J Sex Med. 2014;11:364-73.

6. Buster JE. Managing female sexual dysfunction. Fertil Steril. 2013;100:905-15.

7. Portman DJ, Gass ML, Vulvovaginal Atrophy Terminology Consensus Conference Panel. Genitourinary syndrome of menopause: new terminology for vulvovaginal atrophy from the International Society for the Study of Women's sexual health and the North American Menopause Society. Menopause. 2014;21:1063-8.

8. Sturdee DW, Panay N, International Menopause Society Writing G. Recommendations for the management of postmenopausal vaginal atrophy. Climacteric. 2010;13:509-22.

9. Baber RJ, Panay N, Fenton A, I. M. S. Writing Group. 2016 IMS Recommendations on women's midlife health and menopause hormone therapy. Climacteric. 2016;19:109-50.

10. Rahn DD, Carberry C, Sanses TV, Mamik MM, Ward RM, Meriwether KV, et al. Vaginal estrogen for genitourinary syndrome of menopause: a systematic review. Obstet Gynecol. 2014;124:1147-56.

11. Gass MLS. Management of symptomatic vulvovaginal atrophy: 2013 position statement of the North American Menopause Society. Menopause. 2013;20:888-902 quiz 3-4.

12. Santen RJ. Vaginal administration of estradiol: effects of dose, preparation and timing on plasma estradiol levels. Climacteric. 2015;18:121-34.

13. National Drug Committee. National List of Essential Medicines 2018. In: Health MoP, editor. Nonthaburi 2018.

14. Chompootaweep S, Nunthapisud P, Trivijitsilp P, Sentrakul P, Dusitsin N. The use of two estrogen preparations (a combined contraceptive pill versus conjugated estrogen cream) intravaginally to treat urogenital symptoms in postmenopausal Thai women: a comparative study. Clin Pharmacol Ther. 1998:64:204-10

15. Ziaei S, Rajaei L, Faghihzadeh S, Lamyian M. Comparative study and evaluation of side effects of low-dose contraceptive pills administered by the oral and vaginal route. Contraception. 2002;65:329-31.

16. Souka AR, Kamel M, Einen MA, Saleh F, Sallam H. Vaginal administration of a combined oral contraceptive containing norethisterone acetate. Contraception. 1985;31:571-81.

17. Utian $\mathrm{WH}$. The international menopause society menopause-related terminology definitions. Climacteric. 1999:2:284-6.

18. Tungmunsakulchai R, Chaikittisilpa S, Snabboon T, Panyakhamlerd K, Jaisamrarn U, Taechakraichana N. Effectiveness of a low dose testosterone undecanoate to improve sexual function in postmenopausal women. BMC Womens Health. 2015;15:113.

19. Rosner B. Fundamentals of biostatistics. 7th ed. Boston: Brooks/Cole, Cengage Learning; 2011.

20. Rosen R, Brown C, Heiman J, Leiblum S, Meston C, Shabsigh R, et al. The female sexual function index (FSFI): a multidimensional self-report instrument for the assessment of female sexual function. J Sex Marital Ther. 2000;26:191-208.

21. Ozkinay E, Terek MC, Yayci M, Kaiser R, Grob P, Tuncay G. The effectiveness of live lactobacilli in combination with low dose oestriol (Gynoflor) to restore the vaginal flora after treatment of vaginal infections. BJOG. 2005; 112:234-40

22. Peterson E. Bedeutung der Laktobazillen als Normalflora. Gynakologe. 1985; 18:128-30. 
23. Yörük $P$, Uygur $M$, Erenus $M$, Eren $F$. The role of vaginal maturation value assessment in prediction of vaginal $\mathrm{pH}$, serum FSH and E2 levels. Marmara Med J. 2006;19:52-7.

24. Meisels A. The maturation value. Acta Cytol. 1967;11:249.

25. Stupnicki $R$, Teter J. A dynamic approach to the evaluation of oestrogenic effects on the vaginal epithelium in women. J Reprod Fertil. 1970;22:563-7.

26. Tuntiviriyapun $\mathrm{P}$, Panyakhamlerd $\mathrm{K}$, Triratanachat $\mathrm{S}$, Chatsuwan $\mathrm{T}$, Chaikittisilpa S, Jaisamrarn U, et al. Newly developed vaginal atrophy symptoms II and vaginal pH: a better correlation in vaginal atrophy? Climacteric. 2014;18:246-51.

27. Thomas HN, Thurston RC. A biopsychosocial approach to women's sexual function and dysfunction at midlife: A narrative review. Maturitas. 2016;87: 49-60.

28. Wiegel M, Meston C, Rosen R. The female sexual function index (FSFI): crossvalidation and development of clinical cutoff scores. J Sex Marital Ther. 2005;31:1-20.

29. Constantine G, Graham S, Portman DJ, Rosen RC, Kingsberg SA. Female sexual function improved with ospemifene in postmenopausal women with vulvar and vaginal atrophy: results of a randomized, placebo-controlled trial. Climacteric. 2015;18:226-32.

30. Ettinger $B$, Hait $H$, Reape $K Z$, Shu H. Measuring symptom relief in studies of vaginal and vulvar atrophy: the most bothersome symptom approach. Menopause. 2008;15:885-9.

31. Lee KH, Lee DJ, Kim SM, Je SH, Kim EK, Han HS, et al. Evaluation of effectiveness and safety of natural plants extract (Estromon ${ }^{\circ}$ ) on Perimenopausal women for 1 year. J of Korea Society of Menopause. 2005; 11:1-11.

32. Chang A, Kwak BY, Yi K, Kim JS. The effect of herbal extract (EstroG-100) on pre-, peri- and post-menopausal women: a randomized double-blind, placebo-controlled study. Phytother Res. 2012;26:510-6.

33. Coutinho EM, de Souza JC, da Silva AR, de Acosta OM, Alvarez F, Brache V, et al. Comparative study on the efficacy and acceptability of two contraceptive pills administered by the vaginal route: an international multicenter clinical trial. Clin Pharmacol Ther. 1993;53:65-75.

34. Coutinho EM, Mascarenhas I, de Acosta OM, Flores JG, Gu ZP, Ladipo OA, et al. Comparative study on the efficacy, acceptability, and side effects of a contraceptive pill administered by the oral and the vaginal route: an international multicenter clinical trial. Clin Pharmacol Ther. 1993;54:540-5.

35. Coutinho EM, O'Dwyer E, Barbosa IC, Gu ZP, Shaaban MM, Aboul-Oyoon M, et al. Comparative study on intermittent versus continuous use of a contraceptive pill administered by vaginal route. Contraception. 1995;51: $355-8$.

36. Alexander NJ, Baker E, Kaptein M, Karck U, Miller L, Zampaglione E. Why consider vaginal drug administration? Fertil Steril. 2004;82:1-12.

37. Srikrishna S, Cardozo L. The vagina as a route for drug delivery: a review. Int Urogynecol J. 2012;24:537-43.

38. Hussain A, Ahsan F. The vagina as a route for systemic drug delivery. J Control Release. 2005;103:301-13.

39. Pschera H, Hjerpe A, Carlstrom K. Influence of the maturity of the vaginal epithelium upon the absorption of vaginally administered estradiol-17 beta and progesterone in postmenopausal women. Gynecol Obstet Investig. 1989:24:204-7.

40. Villanueva B, Casper RF, Yen SS. Intravaginal administration of progesterone: enhanced absorption after estrogen treatment. Fertil Steril. 1981;35:433-7.

41. Cicinelli E. Intravaginal oestrogen and progestin administration: advantages and disadvantages. Best Pract Res Clin Obstet Gynaecol. 2008;22:391-405.

42. Caruso S, Cianci S, Amore FF, et al. Quality of life and sexual function of naturally postmenopausal women on an ultralow-concentration estriol vaginal gel. Menopause. 2016;23(1):47-54

43. Gast MJ, Freedman MA, Vieweg AJ, et al. A randomized study of low-dose conjugated estrogens on sexual function and quality of life in postmenopausal women. Menopause. 2009;16(2):247-56.

44. Kim SJ, Jin SW, Lee GH, Kim YA, Jeong HG. Evaluation of estrogenic activity of extract from the herbal mixture Cynanchum wilfordii Hemsley, Phlomis umbrosa Turczaninow, and Angelica gigas Nakai. Toxicol Res. 2017;33:71-7.

\section{Publisher's Note}

Springer Nature remains neutral with regard to jurisdictional claims in published maps and institutional affiliations.

\section{Ready to submit your research? Choose BMC and benefit from:}

- fast, convenient online submission

- thorough peer review by experienced researchers in your field

- rapid publication on acceptance

- support for research data, including large and complex data types

- gold Open Access which fosters wider collaboration and increased citations

- maximum visibility for your research: over $100 \mathrm{M}$ website views per year

At $\mathrm{BMC}$, research is always in progress.

Learn more biomedcentral.com/submissions 